\title{
INCLUSÃO ESCOLAR E DEFICIÊNCIA VISUAL: TRAJETÓRIA E PROCESSO ${ }^{1}$
}

\author{
Maria de Jesus Cano MIRANDA ${ }^{2}$
}

\begin{abstract}
RESUMO: O presente trabalho é resultado de uma pesquisa de campo para estudar a temática da inclusão de crianças com deficiência no ensino regular. Objetiva analisar o processo de inclusão de alunos com deficiência visual em escolas da rede municipal de uma cidade do interior do estado do Paraná, Brasil, bem como refletir a respeito do processo educativo desses indivíduos, levando em consideração a capacidade dos mesmos para a aprendizagem. Metodologicamente o estudo pauta-se nos pressupostos da Teoria HistóricoCultural desenvolvida por Vygotsky e seus colaboradores. Dentre os procedimentos metodológicos adotados destacam-se as entrevistas semi-estruturadas individuais. A análise dos depoimentos dos entrevistados demonstra a complexidade do processo de inclusão. Fica evidenciado que para se alcançar a efetivação das propostas inclusivas, há que se pensar em projetos de forma a contemplar a construção de uma nova sociedade, uma nova ordem em que o homem seja o centro de todas as preocupações e a educação seja entendida como um dos pilares fundamentais para o desenvolvimento do ser humano e para a construção de um mundo mais socializado e humano. Trata-se de uma tarefa difícil em que se devem ponderar fatores de maior amplitude, ou seja, considerar um processo em construção que, por sua vez, está permeado de contradições, conflitos, avanços e recuos, interesses políticos, sociais e econômicos.
\end{abstract}

PALAVRAS-CHAVE: Educação. Deficiência visual. Inclusão.

\section{Introdução}

O estabelecimento das propostas inclusivas para os alunos com deficiências ingressarem na rede regular de ensino está provocando mudanças na compreensão e aceitação dos problemas das deficiências e mobilizando a escola para organizar-se diferentemente, desde sua estrutura funcional, seus princípios filosóficos até seu projeto político-pedagógico. Diante deste fato, o poder público necessita fundamentar-se em pressupostos democráticos que norteiem suas ações e garantam aos seus cidadãos o direito à educação.

O processo educativo das crianças em geral, implica o envolvimento de ações deliberadas e intencionais dos seus responsáveis para alcançarem, com êxito, os objetivos

\footnotetext{
${ }^{1}$ O presente texto, com algumas adequações, foi extraído da Dissertação de Mestrado intitulada Educação, Deficiência e Inclusão no Município de Maringá, defendida em dezembro de 2001 - Universidade Estadual de Maringá - (UEM) - Paraná - Brasil, orientada pela professora Doutora Nerli Nonato Ribeiro Mori.

${ }^{2}$ Doutoranda em Educação Escolar. UNESP - Universidade Estadual Paulista. Faculdade de Ciências e Letras Programa de Pós-Graduação em Educação Escolar. Araraquara - SP - Brasil. 14800-901. UEM - Universidade Estadual de Maringá. Departamento de Teoria e Prática da Educação. Maringá - PR - Brasil. 87020-900 mjcmiranda@uol.com.br
} 
propostos. A educação das pessoas com deficiência visual não é diferente, pois além destas ações torna-se importante uma compreensão mais aprofundada a respeito das especificidades e das reais implicações determinadas pela dificuldade de enxergar.

Dessa forma, o presente texto, cumpre o propósito de analisar o processo de inclusão de alunos com deficiência visual em escolas da rede municipal de uma cidade do interior do estado do Paraná, Brasil, bem como refletir a respeito do processo educativo desses indivíduos, levando em consideração a capacidade dos mesmos para a aprendizagem, desde que apoiados por metodologias adequadas que atendam suas necessidades.

Os embates que envolvem a viabilização de um projeto de inclusão vão além de todas as previsões estabelecidas durante seu planejamento. Acredita-se que, por mais debatido que seja o assunto no nível teórico, ele precisa ser antes de tudo ser assimilado, incorporado, pelas pessoas envolvidas nesse processo, como princípio e enquanto postura profissional. Sob esse prisma, o compromisso do educador passa a ser com a emancipação humana de seus alunos.

Embora os paradoxos da atual sociedade capitalista ofusquem a compreensão dos fatos, é normal deparar-se com inúmeras questões que angustiam educadores comprometidos com a complexidade do fazer pedagógico. Por isso, é importante aprofundar a reflexão sobre o tema e a partir das principais questões que emergem de seus encaminhamentos teóricopráticos.

É possível falar em inclusão, ainda que seja de uma minoria, como é o caso das pessoas com deficiência, na sociedade capitalista tal como ela está organizada hoje? Seria necessário falar de inclusão, se a sociedade estivesse organizada sob outra lógica? A escola que se tem hoje dá conta de incluir os alunos com deficiência? O professor do ensino regular está preparado para ensinar os alunos com deficiência e os demais alunos ao mesmo tempo? A comunidade escolar possui suficiente compreensão do problema, para lidar com ele sem discriminações e preconceitos? Faz parte da cultura a prática da solidariedade e o respeito pela diversidade? Dessas questões se impõem outras de dimensões mais complexas, tais como: em que condições a cidadania do indivíduo comum é considerada? Em que medida os direitos de cidadão, proclamados pelas leis, são devidamente respeitados? E, assim, é possível elencar uma série de outras questões que levam a refletir sobre a situação de inclusão de grupos minoritários na atual sociedade.

A idéia da democratização do ensino como possibilidade de manter todas as crianças na escola, e o ideal de uma escola de qualidade para todos parecem não ser suficientes para garantir posturas coerentes de toda a comunidade educacional, para receber os alunos com deficiências. 
A democratização do ensino pressupõe garantir a todos o direito de participar do processo de escolarização. Para democratizar a educação, há que se democratizar a oferta de vagas na escola, atendendo à diversidade das demandas populares, inclusive as pessoas com deficiência. Garantir escolarização de qualidade para todos implica aceitar e valorizar a diversidade das classes sociais as condições concretas e o estilo de cada indivíduo para aprender.

\section{Metodologia}

O estudo pauta-se nos pressupostos da Teoria Histórico-Cultural desenvolvida por Vygotsky e seus colaboradores. Trata-se de uma pesquisa de campo, cujos procedimentos utilizados para sua realização compõem-se de diferentes ações e instrumentos, tais como: análise de documentos oficiais e extra-oficiais; consultas em arquivos de órgãos oficiais; pesquisa bibliográfica e eletrônica; entrevistas semi-estruturadas individuais e coletivas.

Para a realização das entrevistas foram elaborados quatro roteiros com questões a serem aplicados com os participantes da pesquisa, ou seja: os alunos incluídos, as professoras do ensino especial e do ensino regular e os componentes das equipes técnico-administrativas das escolas envolvidas. O roteiro das entrevistas semi-estruturadas para cada grupo foi organizado obedecendo três categorias previamente selecionadas, julgadas necessárias e significativas para alcançar os objetivos propostos para esta parte da pesquisa. Essas categorias podem ser definidas como: a) caracterização dos sujeitos; b) conhecimento sobre a inclusão; c) prática pedagógica e a inclusão.

Em cada categoria, foi elaborado um rol de questões que formaram um esboço de informações, expectativas e problemas a serem investigados relacionados com o tema central do presente trabalho e com os pressupostos teóricos que o embasam. Não se pretende, com isto, esgotar as diferentes abordagens que emergem de uma discussão desta natureza, mas contribuir para a indicação de elementos que promovam uma reflexão mais crítica e subsidiada a respeito da inserção do aluno com deficiência visual no ensino regular.

O grupo de alunos estudado, bem como os professores do ensino regular e da educação especial e membros das equipes técnico-administrativas referem-se aos participantes do Projeto de Descentralização do Atendimento à Pessoa com Deficiência Visual, implantado pela Secretaria de Educação e Cultura do município campo da pesquisa, o qual tem por objetivo a inserção do deficiente visual na rede comum de ensino, com apoio pedagógico especializado dentro da própria escola que o mesmo freqüenta ou próximo a ela. 


\section{Conceito e caracterização da deficiência visual}

Iniciar um estudo sobre deficiência visual implica primeiramente explicitar o seu significado. As pessoas consideradas com deficiência visual caracterizam-se por uma incapacidade ou limitação no ato de "ver”. Em outras palavras, entende-se por deficiência visual, uma impossibilidade total ou parcial da capacidade visual, conseqüência de alterações no globo ocular ou no sistema visual.

Portanto, no grupo de pessoas com deficiência visual, são incluídos os cegos e os de visão subnormal ou visão reduzida. De forma que de um grupo para outro existe uma variação de perdas que se caracteriza por diferentes graus de acuidade visual. Esta variação pode representar uma perda desde a percepção de luz até o limiar da normalidade.

A caracterização da deficiência visual está relacionada aos fins a que ela se destina. A avaliação clínica, realizada pelo oftalmologista, prende-se à medida objetiva e quantitativa e à detecção da patologia. É necessária para fins econômicos, legais e administrativos. Portanto, segundo a Organização Mundial da Saúde, uma pessoa é considerada cega quando apresenta uma acuidade de 20/200, ou 0,1 no melhor olho, após máxima correção óptica ou quando, informam Cruickshank e Johnson (1983, p.4), o indivíduo apresenta no seu campo visual um ângulo não maior do que 20 graus, “[...] ainda que sua acuidade visual nesse estreito campo possa ser superior a 20/200.” Também denominada de “cegueira legal”, “cegueira econômica”, “visão em túnel”, ou “em ponta de alfinete”, ou ainda, "visão tubular”. 3 As pessoas que possuem acuidade visual entre 20/200 e 20/70 são consideradas deficientes visuais do grupo de visão subnormal ou visão reduzida.

Atualmente os educadores estão valorizando a avaliação funcional da visão, realizada pelo professor, com a finalidade de complementar a avaliação clínica. Esta avaliação com fins educacionais consiste na observação criteriosa da capacidade visual da criança, revelando os possíveis recursos utilizados pela mesma no aproveitamento de seu resíduo visual.

Trata-se de uma forma de avaliar privilegiando os aspectos qualitativos. Com base nesse inventário de informações, o professor pode elaborar um programa educacional mais adequado a cada indivíduo. As representantes mais expressivas desta conduta educacional do

\footnotetext{
${ }^{3}$ No Brasil e nos Estados Unidos, a acuidade de 0,1 ou $20 / 200$ é considerada cegueira legal para fins de aposentadoria, seguro etc.
} 
trabalho de avaliação funcional da visão são as doutoras Eleonora Faye (1972) e Natalie Barraga (1985).

No Brasil, os educadores, profissionais da área e órgãos oficiais, como o Ministério da Educação e Cultura/Secretaria de Educação Especial (MEC/SEESP-BRASIL-1995) e a Secretaria de Estado da Educação do Paraná/Departamento de Educação Especial (SEED/ DEE-PARANÁ-1994), adotaram tais concepções, como orientadoras no atendimento das pessoas deficientes visuais com visão subnormal.

Ao voltar o olhar para a história, percebe-se que a cegueira sempre preocupou a humanidade. Segundo Hugonnier e Clayette (1989), são diferentes os sentimentos que movem os homens no tratamento da pessoa cega. Compaixão, temor ou admiração misturam-se através dos tempos. O próprio Homero, que era cego, na antiguidade, ainda hoje é celebrizado por seus poemas sobre a História do Mundo como a Ilíada e a Odisséia.

Amiralian (1997) destaca também as diferentes maneiras com que a pessoa cega foi e é vista nas diferentes culturas. Evidencia que uma delas é a visão do cego com poderes sobrenaturais, possuidor de dons divinos e misteriosos. A autora trabalha esta temática de forma interessante, enfocando as diversas concepções e abordagens a respeito das pessoas com cegueira ${ }^{4}$.

A Síria, Jerusalém e a França, nos séculos V, VII, X, XI e XII, foram precursores em providenciar assistência e alojamento aos cegos, com a fundação de asilos e lares. A idéia de ensinar-lhes um ofício e reintegrá-los à sociedade foi desenvolvida por Valentin Hauy, em 1784, com a fundação do Instituto Nacional dos Jovens Cegos, em Paris.

Em 1825, Luis Braille, aluno e depois professor do referido Instituto, encarregou-se de elaborar um sistema de escrita baseado nos pontos em relevo, perceptíveis ao tato. Este sistema consiste em uma pequena cela composta de seis pontos, cuja combinação dos mesmos permite a codificação das letras do alfabeto, os numerais, a pontuação e os sinais matemáticos. Dessa maneira, a escolarização dos cegos foi facilitada e aos poucos foi expandindo-se. Porém, somente em 1911, na Alemanha, foi fundada a primeira classe para atender aos amblíopes. Mais tarde, na França, também foi criada uma classe com o objetivo de dar escolarização e formação profissional aos deficientes visuais, diferentemente do atendimento ofertado para os cegos.

Sabe-se que uma boa parte das informações que chegam ao conhecimento do ser humano são transmitidas pelo canal visual. A visão é o sentido responsável pela captação de

\footnotetext{
${ }^{4}$ Sugere-se leitura do capítulo I do livro Compreendendo a cegueira: uma visão psicanalítica da cegueira por meio de desenhos - estórias (AMIRALIAN, 1997).
} 
estímulos e projeções espaciais, facilitando a vida do homem no relacionamento com seus semelhantes. Através da visão, as pessoas podem identificar objetos, distinguir cores, formas, tamanhos, distâncias, gestos e signos além das noções de luminosidade. Certas habilidades como observar, comparar, seguir modelo, deduzir, interpretar e até mesmo controlar são mais favoravelmente desenvolvidas com as ajudas dos canais visuais, como exemplifica Ferrel (1999, p.15): “[...] quando você enxerga bem, vê, o tempo todo, o que acontece a seu redor. Se quiser, pode fechar seus olhos no momento que desejar não vê. Com a visão você tem o controle de tudo. Entretanto, quando não vê bem, a história é diferente.”

Assim, uma pessoa desprovida da capacidade visual tem que lidar com uma gama de obstáculos que poderão afetar seu desenvolvimento psicomotor, intelectual e sócio-emocional, se não receber atendimento especializado tão logo seja detectado seu problema. A experiência educacional com as pessoas com deficiência visual tem mostrado o quanto eles se beneficiam de um trabalho bem planejado e consistente voltado para o desenvolvimento de áreas que são afetadas pela falta de visão. A educação especial dispõe de metodologias específicas que ajudam o aluno com deficiência visual a desenvolver-se e viver integrado no seu meio social.

\section{Desenvolvimento da pesquisa e resultados}

Das 37 escolas que compõem a rede municipal da cidade campo da pesquisa apenas seis escolas integram o projeto mencionado anteriormente, cujas denominações, neste trabalho, estão designadas por letras do alfabeto para preservar a identidade das mesmas, ou seja, E, F, G, H, I, J, respectivamente. Participaram das entrevistas oito professoras do ensino regular, cinco professoras do ensino especial, 17 membros das equipes técnicoadministrativas e sete alunos deficientes visuais incluídos no ensino regular, os quais freqüentam um programa especializado, Centro de Atendimento Especializado para Deficientes Visuais (CAEDV), em horário contrário das classes regulares.

\section{Os alunos}

Da caracterização dos participantes da pesquisa resulta que dos sete alunos com deficiência visual entrevistados, dois pertencem ao sexo feminino e cinco ao sexo masculino. Possuem idade entre cinco e doze anos. Em relação à escolaridade constata-se que dois são do pré-escolar, dois da segunda série, um da terceira série e dois freqüentam a quarta série do ensino fundamental. 
Quanto ao grau de deficiência verifica-se que quatro alunos possuem visão subnormal, ou seja, possuem algum resíduo visual em diferentes graus, ocasionada por patologias diversas e o principal recurso pedagógico é a ampliação das letras em tinta. Os outros três alunos são cegos, utilizam o Braille e o Sorobã como recursos didáticos para aquisição dos conteúdos acadêmicos.

Todos esses alunos passaram pela avaliação de um médico oftalmologista e pela avaliação educacional, a qual é realizada por uma professora especializada em deficiência visual e credenciada para avaliar pela Secretaria Estadual de Educação. Essas crianças freqüentam, num período, as séries da escola regular e, no outro, o Centro de Atendimento Especializado para o Deficiente Visual (CAEDV) para apoio escolar e adequação de material.

Com relação à segunda categoria, que se refere ao conhecimento a respeito da inclusão o grupo mostra que possui conhecimento a respeito da deficiência e da inclusão dessas pessoas no ensino regular, pois emitem suas opiniões com julgamentos positivos.

Na terceira categoria, a qual se refere ao aluno com deficiência frente à inclusão escolar, os participantes do grupo mostram que se sentem bem com seus colegas de turma tanto no ensino especial como no ensino regular. As falas dos alunos pesquisados indicam que há entrosamento, amizade, trocas e interações entre os colegas de turma. Eles não sentem rejeição por parte dos amigos que sabem mais ou que não são deficientes. Como confirmam os depoimentos:

Eu me sinto muito bem, tenho amigos, gosto muito deles e acho que eles gostam de mim. [...] Na sala de aula um ajuda o outro para fazer as tarefas de matemática e de ciências, nas provas eles ditam as perguntas pra mim. Quando eu perco alguma folha um deles vai na minha casa ditar para mim. (EF)

Quanto às atividades que desempenham fora do horário escolar, as crianças desse grupo apresentam uma peculiaridade. Todas freqüentam, obrigatoriamente, aulas na educação especial, no período contrário ao do ensino regular. As sessões são duas ou três vezes por semana com duração de duas horas cada. O objetivo desse atendimento visa o acompanhamento escolar do deficiente visual, como, também, a complementação curricular nas matérias específicas, ou seja, Braille, Sorobã, Orientação e Mobilidade ou adequação do material em tinta. Além dessas atividades, quatro crianças desse grupo freqüentam aulas de música e canto em outra escola. Os outros três alunos, no tempo que lhes resta, desenvolvem atividades diversas, brincam, passeiam, visitam parentes.

Das sete crianças entrevistadas, todas fazem uma projeção para suas vidas no futuro, querem exercer uma profissão, não se sentem impedidas de se realizarem profissionalmente. 
Três crianças manifestam o desejo de serem cantoras, uma quer ser professora, outra deseja ser professor de matemática, outra advogada e outra quer ser do exército. Vale ressaltar o nível de maturidade com que as crianças opinam sobre suas futuras profissões.

Bom, no futuro eu quero ser um bom cantor que nem o Leonardo, e também gravar um CD e ter muitos discos como os cantores têm, para dar um para cada um dos meus amigos. Porque quando eu crescer eu ainda vou ser amigo de todo mundo, eu não vou esquecer deles. [...] Eu gostaria de fazer aula de violão e órgão. Já que estamos falando de ser cantor eu quero também aprender a tocar gaita porque tem um som mais radical. Quando eu crescer eu vou ter alguém para me acompanhar na música e também formar um grupo e ter bailarinas como o Rio Negro e Solimões. (EG)

Ao analisar detalhadamente as respostas dos alunos entrevistados reafirmam-se alguns dos princípios fundamentais promulgados pela Declaração de Salamanca (ESPANHA, 1994), quando se refere às novas idéias sobre as necessidades das pessoas com deficiência. Uma delas é a de que todas as crianças devem aprender juntas, sempre que possível, para que haja interações e trocas mútuas de experiências enriquecedoras e estimuladoras do desenvolvimento não só cognitivo, como afetivo e social dos educandos.

Vygotsky (1989) ${ }^{5}$ também é um dos defensores deste princípio e explica que a criança com deficiência não é simplesmente menos desenvolvida em determinados aspectos, mas alguém que se desenvolve de uma outra maneira. Ele concentra sua atenção nas habilidades que tais crianças possuem, interessando-se mais por suas capacidades do que por suas faltas. Enfatiza que, por meio da inserção na cultura e da participação no processo de construção histórica, a criança com deficiência assimila as formas sociais de atuação, internaliza-as e interage como sujeito histórico. A internalização do conhecimento socialmente produzido e sua reelaboração individual são mediadas pela linguagem, que recodifica as ações da própria pessoa e sua interlocução com as demais. É um constante interagir entre a história social e a história individual.

As concepções de Vygotsky quando se refere às pessoas com deficiências, refletem sua crença na possibilidade de os mesmos se desenvolverem como cidadãos. Opõe-se à tendência de entender a deficiência apenas pelo aspecto orgânico, ou seja, o lado do defeito. Argumenta ainda, que o entrave maior no desenvolvimento da criança com deficiência não é tanto o defeito de caráter biológico e sim as restrições no campo social que impedem uma educação adequada baseada em métodos e procedimentos especiais que lhe permitam um

\footnotetext{
${ }^{5} \mathrm{O}$ nome deste autor é escrito de diferentes formas na literatura consultada, dependendo do idioma. Assim, na língua inglesa utiliza-se a grafia Vygotsky. Em espanhol, Vygotski. Em alemão, Wygotski. As edições traduzidas diretamente do russo para o espanhol adotam a grafia Vigotski. Neste trabalho, com o fim de padronizar o termo, será adotada a grafia Vygotsky, independente do idioma da obra em referência.
} 
desenvolvimento semelhante às crianças normais. A seguinte afirmação ilustra com propriedade seu pensamento: “O cego e o surdo estão aptos para exercer todos os aspectos da conduta humana, quer dizer da vida ativa; a questão particular de sua educação se reduz apenas à substituição de umas vias por outras para a formação das conexões necessárias.” (VYGOTSKY, 1989).

Complementa, ainda: “A cegueira é um fato psicológico, não é uma desgraça. Esta se converte em desgraça como fato social [...]. Decididamente todas as particularidades psicológicas da criança com deficiência têm a base não só no núcleo biológico, e sim no social.” (VYGOTSKY, 1989, p.58).

Vygotsky estabelece os princípios fundamentais que embasam o desenvolvimento da criança com deficiência. Se, por um lado, a deficiência impõe limitações ao indivíduo dificultando seu desenvolvimento, por outro, justamente por ocasionar dificuldades, possibilita o movimento para a compensação, ampliando o desenvolvimento de outras capacidades.

Para o autor, o próprio organismo possui um esquema de compensação das funções deficitárias. Ele afirma que se um órgão, por deficiência funcional ou orgânica, encontra-se impossibilitado de realizar sua função, o sistema nervoso central, juntamente com o aparato psicológico, assume o papel de compensar essa função deficiente que, ao entrar em contato com o meio exterior, estabelece um conflito que origina elevadas possibilidades para a compensação e a supercompensação. Assim, a deficiência se converte em ponto de partida e força motriz para o desenvolvimento psíquico da criança.

Nesta perspectiva, a escola de qualidade, que sabe lidar com a diversidade, busca assegurar às crianças oportunidade de aprenderem juntas, embora tenham objetivos diferentes.

As respostas das crianças são ricas em pormenores que evidenciam a naturalidade como elas convivem no espaço escolar, compartilhando vivências próprias da infância, no que se refere ao fazer acadêmico, às relações sociais e ao brincar. Percebe-se que os alunos com deficiência visual que possuem dificuldades específicas determinadas pela ausência ou limitação da visão conseguem interagir com os demais colegas, seja nas brincadeiras, na realização das tarefas escolares ou nas interações sociais.

\section{As equipes técnico-administrativas}

Para os membros das equipes pedagógicas, a educação deve estar sempre em constante mudança, procurando novas alternativas para melhorar a qualidade de ensino dos alunos na 
sua diversidade, para que estes permaneçam na escola, inclusive as crianças com deficiência devem receber atendimento específico às suas reais necessidades.

Os profissionais das escolas consideram a necessidade de construir uma Proposta Pedagógica que garanta aos alunos uma efetiva participação no processo educativo, apropriando-se do conhecimento para usufruírem de forma ativa dos bens culturais que foram legados pela humanidade. Para essas equipes, a escola é entendida como o espaço que possibilita discussões coletivas, favorecendo o enriquecimento pessoal e social por meio das interações. Sobretudo, uma escola que esteja a serviço das camadas populares, em que o professor seja um educador comprometido com a defesa dos princípios democráticos.

Nesse sentido para Vygotsky (1989) a educação especial deve fazer parte da educação geral. Embora tenha atribuído críticas à educação especial, considera seus méritos. A escola especial não pode continuar enclausurando os educandos num mundo restrito e separado, limitando o desenvolvimento global dos mesmos. Ao contrário, a prática pedagógica destinada às crianças com deficiência deve basear-se na educação social, seja qual for o tipo de deficiência, cegueira, surdez ou retardo mental, acarreta algum tipo de desajuste social. Portanto, do ponto de vista pedagógico, a educação das crianças com deficiência implica, necessariamente, em oportunizar sua inserção social.

Vygotsky (1989) afirma que a escola especial tem sido anti-social, por isso forma o indivíduo anti-social, ao criar uma ruptura sistemática entre a pessoa com deficiência e o ambiente normal. Especificamente, em relação à escola especial para cegos, o autor a denomina de ambiente artificial que não tem nada em comum com o mundo normal em que o cego deve viver. É uma escola que não ajuda na superação da cegueira e sim acentua sua condição, limitando o cego a viver num mundo segregado. Por isso recomenda:

Devemos pensar em como incluir e integrar o cego, o mais cedo possível, na
vida. O cego deve viver uma vida em comum com os videntes e, para isso,
deve estudar na escola regular. É certo que os elementos específicos do
ensino especial devem ser preservados na escola especial ou introduzi-los na
escola comum. Em princípio deve-se integrar os dois sistemas. Com o fim de
vencer o espírito anti-social da escola especial é necessário realizar uma
experiência cientificamente fundamentada no ensino e na educação
compartilhada, entre cegos e videntes. Experiência que tem futuro
promissor. (VYGOTSKY, 1989, p.64).

Vygotsky mostra, por meio de seus estudos, as semelhanças no modo de desenvolver da criança com deficiência e da criança normal. As crianças com deficiências necessitam, segundo ele, apenas de peculiaridades metodológicas para chegarem ao pensamento abstrato. Para o autor, não há diferença no enfoque educativo da criança com deficiência e da criança 
considerada normal. Considera um erro ver a anormalidade pelo enfoque da doença. Aconselha que não se deve avaliar as crianças pelo comprometimento que apresentam e sim pelas áreas íntegras que possuem.

Propõe mudanças radicais a esse modelo rígido das escolas especiais. E a saída que ele aponta não é a caridade social e sim uma lei geral de educação laboral. A educação que ele sugere considera tanto os aspectos psicológicos quanto os pedagógicos. A tarefa da educação, segundo Vygotsky, consiste em incorporar a criança deficiente ao seu meio social e criar a compensação de sua deficiência.

Ao analisar a educação especial e a educação geral, o autor sinaliza que na essência não há diferença de princípios entre a educação da criança deficiente e a educação da criança normal. Porém, há que se admitir a importância da educação especial para a criança deficiente, mas ela deve assumir um caráter científico e não filantrópico. O seguinte trecho mostra a visão do autor

[...] não se pode dizer que não há conhecimentos especiais para os cegos, os surdos e os deficientes mentais. Mas, estes conhecimentos e sua preparação devem submetê-los à educação geral e à formação geral. A pedagogia especial deve ser diluída na atividade geral da criança deficiente (VYGOTSKY, 1989, p.47).

Em outros momentos, o autor retoma a necessidade de mudança no foco da educação das crianças com deficiências. Argumenta dizendo que é preciso libertá-la das marcas e das influências filantrópico-religiosas e reestruturá-la segundo os princípios da pedagogia, com a compreensão científica dos problemas por exigência da realidade.

Vygotsky (1989, p.61), defende com ênfase e vigor a educação da pessoa com deficiência como meio de superação e emancipação da pessoa humana, como ilustra a passagem a seguir:

É provável que mais cedo ou mais tarde a humanidade triunfe sobre a cegueira, sobre a surdez e sobre a deficiência mental. Mas as vencerá no plano social e pedagógico muito antes que no plano biológico e medicinal. É possível que não esteja longe o tempo em que a pedagogia se envergonhe do próprio conceito que tem sobre a criança deficiente, ou seja, considera como um defeito não eliminável de sua natureza. O surdo falante, o trabalhador cego participantes da vida em toda a sua plenitude, não sentirão sua deficiência e não darão motivos para que outros a sintam. Em nossas mãos está tratar de que o surdo, o cego e o deficiente mental não sejam pessoas com defeito [...] o número de cegos e de surdos se reduzirá de um modo incrível. Pode ser que a cegueira e a surdez desapareçam definitivamente. Porém, muito antes, elas serão vencidas socialmente. 
Nessa citação fica evidenciada, uma vez mais, a posição do autor em relação ao desenvolvimento humano com base nas relações sociais e interações dos sujeitos históricos. As contribuições dos pressupostos da teoria vygotskiana apontam para a possibilidade da pessoa com deficiência superar suas dificuldades pelo processo de compensação social. Este processo consiste em criar condições e estabelecer interações sociais de trocas que possibilitem aos sujeitos com deficiência de se apropriarem da cultura, terem acesso ao conhecimento científico e se tornarem emancipados.

Com referência ao segundo tópico pesquisado junto às equipes das escolas, a respeito do conhecimento dos mesmos sobre a inclusão dos alunos com deficiência no ensino regular, foi possível constatar que a maioria das pessoas entrevistadas não possuía esse conhecimento de forma aprofundada, apenas superficialmente com informações pela televisão e as reuniões promovidas pela Secretaria de Educação Municipal. Outros participaram de seminários e palestras sobre o assunto, mas sem muito aprofundamento. Em geral, os membros das equipes colocam que há falta de conhecimento a respeito da temática.

No terceiro tópico da pesquisa, que se refere aos aspectos da escola e a inclusão, percebe-se, uma unidade de conduta que é a crença na possibilidade do trabalho integrado favorecer o desenvolvimento e o aprendizado dos alunos deficientes e não deficientes.

A inclusão trouxe modificação para a escola porque, pelo fato da pessoa com deficiência visual depender de alguém para conduzí-lo foi necessário todo um trabalho com a comunidade escolar para explicar e orientar a respeito dos cuidados para com as pessoas com deficiência visual e observar obstáculos do ambiente, exemplo: portas, cadeiras, pessoas circulando no espaço. Observar a orientação que quando o vidente chega anunciar-se para o cego.

Ao analisar os pontos positivos e negativos que a inclusão trouxe para a escola, os elementos das equipes apontam um pensamento otimista a respeito desse processo, afirmando que é um enriquecimento para todos, uma vez que a freqüência desses alunos, na escola, tem incentivado e estimulado outros alunos a se desafiarem.

Quanto às expectativas da equipe em relação ao presente e ao futuro da inclusão, de um modo geral são boas, mas justificam que o receio e a resistência dos professores do ensino regular têm origem no medo deles não receberem o apoio que poderão necessitar para desenvolver a aprendizagem dessas crianças no decorrer das atividades escola.

Os membros desta mesma equipe enfatizam que ainda há resistência por parte da sociedade e dos profissionais em aceitar a inclusão, em conseqüência talvez da maneira individualista como as pessoas vivam no atual sistema econômico. Eles defendem a 
necessidade de mudanças no modo de ver a própria humanidade no sentido de incluir a todos, as pessoas com deficiência, mas ver as pessoas com um olhar mais humano e solidário.

Outro aspecto relevante, que se destaca ao analisar os dados obtidos nas entrevistas com os componentes das equipes das escolas, refere-se à adequação da escola para atender as necessidades dos alunos. Observa-se que essas escolas em questão empenham esforços para cumprir um dos preceitos estabelecidos pela Declaração de Salamanca (ESPANHA, 1994), que é a pedagogia centrada na criança, à qual a escola deve adequar-se para ensinar, com sucesso, todas as crianças. Trata-se de uma mudança de perspectiva. A pedagogia centrada na criança traz benefícios para todos os alunos, valorizando sempre o potencial de cada um e não suas incapacidades.

\section{As professoras}

O Grupo de professoras entrevistadas é constituído de 13 professoras sendo oito pertencentes ao ensino regular e cinco ao ensino especial.

A respeito do segundo tópico pesquisado nas entrevistas, o qual se refere ao conhecimento que os profissionais possuem sobre a inclusão e suas opiniões sobre o assunto, observa-se que a maioria das professoras concorda com a inclusão dos alunos com deficiência, embora se queixem da falta de conhecimento e preparo para lidar com esses alunos. Porém, nenhuma professora nega-se a recebê-los em suas salas de aula, mesmo sem o conhecimento necessário, alegado por elas, não deixam de atender aos alunos deficientes que lhes foram designados. De uma forma ou de outra o aluno é sempre atendido. Este pensamento revela o caráter místico que ainda acompanha e envolve a educação das pessoas deficientes. O trato das pessoas com deficiência atribui ao ser humano uma força externa e superior. Por mais difícil que se apresente a tarefa, a professora consegue alcançar seus objetivos pelo carinho dedicado e pela luta empreendida no trabalho, e não pela competência profissional que a tarefa de ensinar exige.

Com referência ao tópico das práticas pedagógicas e a inclusão, o grupo entrevistado afirma que acredita no processo de inclusão, admite que os alunos com deficiência visual são beneficiados ao freqüentarem o ensino regular. Argumentam que esses alunos aprendem tanto quanto os alunos denominados normais, necessitando apenas da adequação dos recursos de ensino. Alguns estudantes com cegueira ou de visão subnormal aprendem tão bem os conteúdos das diferentes áreas do conhecimento que se sobressaem e destacam-se dos demais alunos da sala. Uma das professoras entrevistadas cita o caso de seu aluno cego que responde 
em primeira mão e antes dos outros alunos às questões de matemática que lhe são propostas. Estas colocações confirmam a tese defendida por Vygotsky (1989), a respeito do potencial e do desenvolvimento da criança cega. Só atualmente, a disseminação de suas idéias está chegando aos educadores brasileiros. Aos poucos, vêm-se notando avanços nas pesquisas, nos estudos e principalmente na maneira de entender a pessoa com deficiência.

Seu principal interlocutor nesse assunto é Adler, o qual atribui elevada importância ao processo de compensação no desenvolvimento psíquico do ser humano. O autor considera como relevante e importante a reação de toda personalidade diante dos defeitos, assim como os processos de compensação no desenvolvimento. Afirma Vygotsky (1989, p.27 e p.33) que a teoria da compensação descobre o caráter criador do desenvolvimento, citando a seguinte passagem de uma obra de Stern e Adler, publicada em 1923, “tudo que não me destrói me faz forte”. Quer dizer que da insuficiência surge a capacidade e a força para vencer as dificuldades. Complementa, ainda, o autor que “o defeito não é só debilidade, é também força”.

Para o autor, esse processo de compensação sempre desencadeia resultados de êxito. É um processo que se caracteriza pela luta, tanto pode ter sucesso, como fracasso; o importante é observar neste processo o aspecto criador de caráter orgânico e psicológico, que proporcionam construir as funções de adaptação, a formação de novos processos. Em outras palavras seria a formação de novas vias para o desenvolvimento das funções superiores. $\mathrm{O}$ fato de as crianças com deficiências não possuírem as mesmas funções observadas nas crianças normais não quer dizer que elas não possam aprender. Pela lei da compensação, as crianças com deficiências poderão alcançar o desenvolvimento que necessitam por outros meios, por outras vias, ou seja, de um modo diferente. Assim, as crianças cegas e surdas aprendem tanto quanto as crianças normais, desde que seus professores conheçam suas particularidades no modo de aprender. Neste sentido, o autor afirma, "É a lei da transformação do menos da deficiência em mais da compensação que proporciona a chave para chegar a esta peculiaridade.” (VYGOTSKY, 1989, p.7).

Vygotsky enfatiza que o sentimento de inferioridade, provocado pela deficiência, pode converter-se na principal força motriz do desenvolvimento psíquico. Pode ocorrer a supercompensação, transformando a deficiência em talento, capacidade e inteligência. Exemplifica citando vários casos de pessoas que ganharam notoriedade a partir de suas deficiências. Dos tempos antigos, o autor cita o grego Desmóstenes, que tinha problema de linguagem e pelo seu esforço conseguiu ser um grande orador. Da contemporaneidade, o autor 
mencionado, destaca a americana Helen Keller, a qual desafia suas deficiências e torna-se famosa escritora e doutora em filosofia.

Com relação às expectativas sobre o presente e o futuro da inclusão, todas confirmam a crença no movimento da inclusão, ninguém foi contra, porém aproveitam para reivindicar melhor preparo e qualificação para trabalhar com as crianças e o acompanhamento da educação especial.

Todas as professoras do grupo afirmam que o acompanhamento dos alunos que freqüentam o Projeto é feito por contatos informais e pessoais com a professora do ensino regular e no planejamento bimestral com a equipe da escola, momento em que se discutem as dificuldades gerais do aluno, são feitas orientações necessárias para o desenvolvimento do mesmo.

Quanto à metodologia, conteúdos e recursos específicos as professoras informam que não há diferença do que é planejado para os alunos do ensino regular. Embora uma das professoras pontue que nem sempre é possível seguir esse planejamento, às vezes, é necessário fazer algumas adaptações, mas a professora não menciona quais são essas adaptações.

Os recursos específicos são necessários a todos os alunos com deficiência visual para adequação do material, seja ele escrito em Braille ou ampliado em tinta. No modo de aprender não acusam nenhuma diferença tão acentuada, apenas salientaram que os alunos com deficiência visual ficam mais atentos às explicações, não desviam a atenção tão facilmente como os outros alunos e, talvez por isso, conseguem aprender determinados conteúdos com mais facilidade. Os conteúdos trabalhados são os mesmos, não há nenhuma diferença ou alteração no programa de estudos, quando o assunto é muito abstrato existe um esforço de todos, até mesmo da própria criança em encontrar uma estratégia, um meio ou uma alternativa que facilite sua compreensão.

Quanto à dinâmica da sala de aula, todas as professoras alegam não ter interferido em nada a presença do aluno com deficiência visual. Algumas destacam que houve necessidade de conscientização da turma, no sentido de disciplinarem a tonalidade da voz, para que o colega com deficiência visual acompanhe as explicações da professora. Deve-se ter o cuidado de avisar para esse aluno sempre que houver mudanças na disposição das carteiras da sala e manter sempre alguém disponível para auxiliá-lo caso necessite.

As professoras do ensino especial enfatizam que, antes do Projeto de Inclusão, o trabalho do professor junto ao aluno com deficiência visual era um tanto restrito e limitado, por diferentes motivos, dentre eles destacam-se: o ensino das disciplinas específicas (Braille e 
Sorobã) era apenas técnico (mecânico), hoje as professoras precisam acompanhar os conteúdos do ensino regular para ajudar o aluno deficiente visual a apropriar-se dos conteúdos com reflexão, isto está levando a um ensino mais dinâmico; grande resistência (rejeição) por parte das escolas regulares em receber o aluno com problemas visuais, atualmente percebe-se que as escolas estão aceitando melhor este desafio; ensino especial voltado mais para a área da reabilitação não proporcionando o desenvolvimento integral do indivíduo. Outra professora acrescenta que o ensino especializado, funcionando dentro da escola regular, possibilita um intercâmbio muito maior entre professor de educação especial e professor de ensino comum.

Ao levantar os pontos positivos e negativos do processo de inclusão, as professoras entrevistadas evidenciam mais os pontos positivos. Algumas chegam a dizer que não viam pontos negativos nesse processo. Dentre os aspectos positivos mencionados por elas, podem destacar: a convivência social favorece o desenvolvimento integral dos alunos com deficiências, amenizando a visão de incapacidade que lhes era atribuída; os alunos não deficientes aprendem a conviver e a respeitar as diferenças e são, de certa forma, estimulados a se motivarem mais para o estudo, diante do modelo do aluno com deficiência.

Com referência às expectativas em relação ao presente e ao futuro da inclusão, as professoras manifestam-se confiantes e acreditam no processo de inclusão e principalmente a inclusão escolar, embora um tanto desafiador para todos, mas gratificante quando se percebe que o aluno com deficiência está freqüentando a escola regular e prosseguindo seus estudos.

Sabe-se que a visão é o sentido responsável pela captação de estímulos e projeções espaciais, facilitando a vida do homem no relacionamento com seus semelhantes. Segundo os estudos desenvolvidos por Vygotsky (1993), a formação de conceitos é um processo que pressupõe aprendizagens e generalizações obtidas pelo indivíduo, graças à sua vivência no contexto cultural e histórico. Este processo pressupõe, ainda, o emprego funcional das palavras ou outros signos para desenvolver a atenção, a associação, a análise, a combinação de julgamentos e o estabelecimento de relações. De acordo com Facci, (1998, p.132), “[...] signo e a palavra é que permitem ao indivíduo dominar e dirigir suas próprias operações psíquicas, controlando o curso de sua atividade e orientando de forma a resolver a tarefa proposta.”

Desse modo, para que a criança cega se desenvolva intelectualmente e se aproprie adequadamente de conceitos espontâneos e científicos, é necessário um trabalho sistematizado em que se privilegie a linguagem, a vivência de experiências pelas trocas, a mediação de professor especializado, recursos adequados e um ensino que estimule seu desenvolvimento. 
Uma pessoa cega que sempre aprendeu a conhecer os objetos pelo tato e a relacionarse por intermédio dos outros sentidos, se lhe for devolvida a possibilidade de enxergar, não terá o mesmo desempenho que antes para interpretar o mundo pela visão. Ao lado desses dos sentidos remanescentes, aguçados na pessoa cega para apropriar-se dos conceitos e estabelecer uma rede de conexões favoráveis ao desenvolvimento das funções superiores, destaca-se com extraordinária importância o papel da linguagem. A linguagem ocupa um papel de primeira ordem no funcionamento cognitivo do indivíduo cego. De maneira que crianças cegas desde o nascimento devem ser estimuladas a perceberem e apreenderem o mundo com os recursos que dispõem, especialmente porque elas não percebem os olhares, os quais se constituem em recursos utilizados pelas pessoas para comunicarem seus desejos, interesses e manifestarem códigos de aprovação ou reprovação.

Por isto, a educação do deficiente visual deve ser permeada de experiências ricas de trocas e interações que lhe permitam desenvolver seu potencial e superar a deficiência, conquistando sua autonomia, independência e por conseqüência alcançar sua emancipação humana, o que na lógica da sociedade capitalista torna-se um tanto difícil de ocorrer, pelos mecanismos seletivos que possui.

\section{Considerações finais}

No decorrer da presente pesquisa foi possível perceber que os aportes sobre a diferença e a diversidade estão ganhando ênfase e suscitam nas pessoas a necessidade de, cada vez mais, conviverem em uma sociedade desigual e plural, a qual exige também novos encaminhamentos políticos, econômicos, culturais e atitudinais aos problemas decorrentes dessa nova forma de viver e pensar.

Neste sentido, a inserção dos alunos com deficiência visual no ensino regular pressupõe que ela seja estudada tendo em vista a formação educativa e social dos alunos e não apenas as razões de interesses político-econômicos. Deve sim, estar voltada para a perspectiva em que o ser humano seja o motivo principal e inquestionável do progresso e do avanço técnico-científico, possibilitando e favorecendo seu pleno desenvolvimento com vistas à emancipação social e individual.

Nessa linha de raciocínio, a escola da modernidade deve constituir-se no espaço que possibilite, além da construção do conhecimento, também a construção desse novo saber, desse novo viver, alicerçados pelos princípios democráticos e em busca da cidadania. 
De modo que os resultados da presente pesquisa apontam em direção a uma prática pedagógica marcada por uma fase de transição. Ao mesmo tempo em que algumas pessoas entrevistadas, envolvidas com o processo educacional, declaram-se favoráveis ao movimento de inclusão, outras o consideram mais trabalhoso do ponto de vista pedagógico, exigindo mais envolvimento das pessoas que nele atuam.

Verifica-se, portanto, que dos 37 alunos matriculados que freqüentam 6 Centros de Atendimentos Especializado ao Deficiente Visual (CAEDV) existentes nessa rede de ensino, encontram-se inseridos apenas 7 alunos, esse dado mostra o índice de alunos que participam dos projetos de inclusão nesse município, campo da pesquisa, é significativamente reduzido. Esse número de incluídos não justifica a resistência, por parte de alguns membros da comunidade escolar, em não aceitar a inserção do aluno com deficiência no ensino comum. No universo de alunos regulares, cada escola pode inserir um número adequado de alunos com deficiência, de forma planejada, sem que com isto seja alterada a dinâmica da mesma, segundo os depoimentos, já mencionados, das equipes entrevistadas neste estudo.

Em resumo, para se alcançar a efetivação das propostas inclusivas, há que se pensar em projetos de forma a contemplar a construção de uma nova sociedade, uma nova ordem em que o homem seja o centro de todas as preocupações e a educação seja entendida como um dos pilares fundamentais para o desenvolvimento do ser humano e para a construção de um mundo mais socializado e humano. Assim, a inclusão de minorias, como é o caso das pessoas com deficiência, seria um problema a ser tratado numa dimensão mais ampla, ou seja, como uma questão social a ser resolvida conjuntamente pela coletividade, envolvendo governo e sociedade.

Nessa dimensão, os problemas sociais são tratados na abrangência merecida, no caso específico dos indivíduos com deficiência, consistem em subsidiar o aspecto preventivo e profilático, priorizar o caráter educativo e formador e, por último, incentivar o trabalho condizente às suas capacidades.

É importante ressaltar que os estudos realizados nesta pesquisa mostram que o movimento pela inclusão dos alunos com deficiência no ensino regular não teria razão de existir se os valores da sociedade atual estivessem voltados não só para o progresso material, mas também para o desenvolvimento humano e social dos indivíduos, de forma a atender cada um na sua necessidade, desde os mais comprometidos aos mais desenvolvidos, seja na escola especial, seja na escola regular. De modo que o trabalho pedagógico da escola especial seria de tal qualidade que impulsionasse o desenvolvimento das crianças mais afetadas a ponto de elas se tornarem aptas a mudar de modalidade de ensino. Por sua vez, a escola regular estaria 
tão comprometida com sua função de mediadora do conhecimento que seria capaz de formar o cidadão com deficiência e todos os demais.

Como os valores da sociedade capitalista não apontam nessa direção, o fundamental é considerar o homem o centro de todas as ações da sociedade, a fim de promover uma inversão dos valores atuais. É preciso envidar esforços para que as incapacidades de alguns sejam tratadas como problemas sociais em que a própria sociedade encaminhe formas diferenciadas de oportunizar desenvolvimento e inserção desses indivíduos à coletividade, como seres produtivos, respeitando suas capacidades e potencialidades.

Nisso, consiste, talvez, a concepção de uma sociedade diferente desta que aí está. Os cidadãos estão nela inseridos, são parte da comunidade, membros integrados desse todo, que por razão alguma, poderia ser dividida, fragmentada e elitizada.

Os aspectos relevantes encontrados na análise dos Projetos de Integração/Inclusão no Município em questão indicam um redimensionamento dos princípios educacionais dessas escolas, rumo à inversão dos valores aos quais estão postos na sociedade atual. Na medida em que a atividade escolar está voltada para o desenvolvimento do cidadão, seja ele deficiente, negro, pobre, índio...

Para concluir, observa-se que a análise dos depoimentos dos alunos incluídos, das equipes técnico-administrativas das escolas e do grupo de professores que trabalha diretamente com aluno com deficiência visual, seja no ensino especial ou no ensino regular, demonstram a complexidade do processo de inclusão. Não é de um momento para o outro que mudanças desta natureza podem ser operacionalizadas. Trata-se de uma tarefa difícil em que se devem ponderar fatores de maior amplitude, ou seja, considerar um processo em construção que, por sua vez, está permeado de contradições, conflitos, avanços e recuos, interesses políticos, sociais e econômicos.

Enfim, com estes estudos, percebe-se a complexidade e a abrangência do tema, impossível esgotá-lo nas dimensões desse texto. Também se torna difícil considerar este trabalho acabado. O tempo impõe e delimita uma pausa, mas o debate e a reflexão continuam.

\section{A STUDY ABOUT INCLUSION PROCESS OF PUPILS WITH VISUAL DISABILITIES IN SCHOOLS OF PARANÁ, BRAZIL}

ABSTRACT: This work is the result of a field research investigating the inclusion of handicapped children in regular schools. It aims at surveying the inclusion process of pupils with visual disabilities in municipal schools in a city in the province of Paraná, Brazil, as well as ponder over the education process of those individuals, taking into account their 
learning ability. Methodologically, the study is based on the "Historical-Cultural" Theory developed by Vygotsky and his collaborators. Semi-structured individual interviews was the main methodological procedure employed. The analysis of their answers proves the complexity of the inclusion process. It is evident that, to reach effective accomplishment of the inclusive proposals, it is necessary to transform the society, reaching a state where the person is the center of all concerns and the education process is understood as one of the fundamental pillars for human development, leading to a more social and human world. This is an extremely difficult task and more general factors need to be taken into account, considering a construction process embedded in contradictions, conflicts, advances and moves backward, as well as political, social and economical interests.

KEYWORDS: Education. Visual disability. Inclusion.

\section{REFERÊNCIAS}

AMIRALIAN, M. L. T. M. Compreendendo o cego: uma visão psicanalítica da cegueira por meio de desenhos-estórias. São Paulo: Casa do Psicólogo, 1997.

BARRAGA, N. Programa para desenvolver a eficiência no funcionamento visual. São Paulo: Fundação para o Livro do Cego no Brasil, 1985.

BRASIL. Ministério de Educação e Cultura. Secretaria de Educação Especial. Subsídios para organização e funcionamento de serviços de educação especial: área da deficiência visual. Brasília: MEC: SEESP, 1995. (Série Diretrizes, n.8).

CRUICKSHANK, W.; JOHNSON, G. O. A educação da criança e do jovem excepcional. Porto Alegre: Globo, 1983. v.2.

ESPANHA. Ministério da Educação e Ciência de Espanha. Declaração de Salamanca. Salamanca: UNESCO, 1994.

FACCI, M. G. D. O psicólogo nas escolas municipais de Maringá: a história de um trabalho e a análise de seus fundamentos teóricos. 1998. 253 f. Dissertação (Mestrado em Educação)- Faculdade de Filosofia e Ciências, Universidade Estadual Paulista, Marília, 1998.

FAYE, E. E. El enfermo com déficit visual :experiencia clínica en adultos y niños. Barcelona: Editorial Cientifica-Médica, 1972.

FERREL, K. A. A criança deficiente visual e seus pais. Revista Benjamin Constant, Rio de Janeiro, v.5, n.11, p.12-19, 1999.

HUGONNIER-CLAYETTE, S. P. et al. As deficiências visuais: deficiências e readaptações. Tradução de Maria José P. Isaac. São Paulo: Monole, 1989. 
PARANÁ, Secretaria de Estado da Educação. Fundamentos teórico-metodológicos para a educação especial. Curitiba: SEED: DEE, 1994.

VYGOTSKY, L. S. Obras escogidas. Madri: Visor, 1993.

Fundamentos de defectologia. Havana: Editorial Pueblo y Educación, 1989. 